Tarih Kültür ve Sanat Araştırmaları Dergisi

Revue des Recherches en Histoire Culture et Art

$$
\text { مجلة البحوث التاريخية و الثقافية والفنية }
$$

Vol. 6, No. 5, November 2017

Copyright (C) Karabuk University

http://kutaksam.karabuk.edu.tr

\title{
DOI: 10.7596/taksad.v6i5.1268
}

Citation: Bodrova, E., \& Kalinov, V. (2017). Reformation of the Scientific and Technical Sphere in the Russian Federation in the "Transition Period": Plans and Reality in 1990s. Journal of History Culture and Art Research, 6(5), 192-199. doi:http://dx.doi.org/10.7596/taksad.v6i5.1268

\section{Reformation of the Scientific and Technical Sphere in the Russian Federation in the "Transition Period": Plans and Reality in 1990s}

\author{
Elena Vladimirovna Bodrova ${ }^{1}$, Vyacheslav Viktorovich Kalinov ${ }^{2}$
}

\begin{abstract}
The paper analyzes the situation that has been developed after the collapse of the former USSR in the scientific and technical complex of the Russian Federation, which, according to the authors, developed from a crisis situation to a catastrophic one. The conclusion is drawn that its degradation was caused not only by the general paralysis of the socioeconomic sphere, and also by the lack of a conceptually elaborated state industrial, scientific and technical and innovation policy, by the weakness of the legal framework and the erroneous priorities chosen at that time by the reformers. In general, the state scientific and technical policy in the period under review was characterized by inconsistency and persistently unrealized plans.
\end{abstract}

Keywords: Modernization, Rreforms, Scientific community, Scientific research.

\footnotetext{
1 Moscow State Technological University Address: 19454, Moscow, Vernadsky Prospekt, 78. E-mail: bodrova_elena_80@mail.ru

${ }^{2}$ Gubkin Russian State University of Oil and Gas (National Research University) Address: 119991, Moscow, Leninsky Prospect, 65, building 1.
} 


\section{Introduction}

At a new stage of Russian modernization and the critical importance for Russia of a technological breakthrough, we believe it is important and urgent to rethink various aspects of the national history in the post-Soviet period, including the reform of the scientific sphere. One of the most controversial problems of recent years is the experience of catch-up modernizations (Krasilshchikov, 2008; Jomo, 2004). Referring to the experience of Latin American countries, a number of authors believe that the modernization complete control over which given to the market, accompanied by forced liberalization, inattention to own traditions in culture, science, production, and innovation leads to deceleration of modernization processes, lagging, and moreover, neocolonial dependence (Shapiro, 2007). Having carried out a comparative analysis of strategies for countries with economies in transition, Doctor of Economics, Harvard University professor J. Kornai has formulated a fair conclusion in our opinion that macroeconomic stabilization is an endless war; a blitzkrieg did not win it. Institutional reforms need progressive and stepby-step implementation. The famous scientist unexpectedly compared the Russian experience of their implementation in the 90s to Stalin's modernization with many, having revealed much in common: property reforms were subordinated to political ideas, differed in the reluctance of gradual changes and intolerance, obsession with the accelerated pace of change (Kornai, 2000).

Search for the most optimal development strategy for Russia at present; the sharpness of discussions about our past, present and future; the study of a number of previously unpublished archival documents and materials that contain assessments of the late Soviet period in the evolution of state policy in the scientific, technical and educational spheres, which in many respects substantiated the concepts of the need for radical reform of them; letters on the state of the scientific community and the recommendations of scientists sent to the new leadership of the country at the beginning of the so-called "transition period", all this prompted us to publish the results of our research.

\section{Materials and methods}

The basic theory of the study is the theory of modernization, since the idea of development, while forming its essence, insures against changes in the political and geopolitical climate. The peculiarities of the multi-line modernization model include: recognition of the possibility of modernization in one's own path, the importance of external, sociocultural, and subjective factors. We believe that back in 1985, a new, modern stage of Russian modernization began, the first attempt at implementation of which ended in failure, and the subsequent disintegration of the country. We believe that among the main reasons is the lack of worthy accomplishment of this task by the leaders of the country, who did not understand neither the essence of the current trends in the development of the world community, nor the specifics of the Russian model of modernization. We are sorry to admit that the course chosen by the new liberal reformers (some of whom were sincerely mistaken, and some were simply self-interested people), led to even greater failure and lag. It seems that the previously unpublished documents from the funds of the State Archives of the Russian Federation and the Archive of the State Duma of the Federal Assembly of the Russian Federation should confirm this conclusion.

A significant body of scientific works of recent years is devoted to the analysis of the transformation of Russian society in the $90 \mathrm{~s}$ of the $20^{\text {th }}$ century. However, they deal only with certain subjects of the topic of interest to us (see: Kodin, 2002; Osipov, 1999; Plimak \& Pantin, 2000). A large number of publications are devoted to the problems of the implementation of economic policy which also involves the subjects important for us (see: Gordon \& Klopov, 2001; Zudin, 1995; Mau, 1995). A significant part of the authors rightly argues that the experience of integration of the country in the 1990s into the global economy as a result of liberal reforms led to the destruction of the processing industry in its science-intensive part, the 
growth of "raw materials" industries, as well as industries characterized by high energy and water consumption, and toxic emissions (Sukhorukova et al., 2016).

\section{Results}

The archival and other documents and materials studied by us confirm the conclusion that in the postSoviet period the reformers received a rather heavy aftermath: by early 1992, both in the country and in the scientific and technical sphere, a crisis situation had developed. On February 11, 1992, parliamentary hearings "Science and Education in the Conditions of Price Liberalization" were held, where, in particular, the country's leadership was urged to approve the draft decree with the title speaking a lot: "On Urgent Measures to Preserve Russia's Scientific and Technical Potential..." (GARF, 55: 201-202).

It is difficult to disagree with the characteristics of the state of the scientific and technical potential of the Russian Federation as a critical one obtained in the beginning of 1992 by the experts of the Ministry of Science, Higher School and Technical Policy of the Russian Federation: a powerful scientific and technical complex of the country was going through hard times. At that time, organizations and enterprises of the Russian Federation engaged in scientific and technical work accounted for more than $60 \%$ of all organizations and enterprises located in the territory of the former USSR and performing such work. In defense and academic science, this share was $70-80 \%$. Only for 1991 the number of employees of the main activity in scientific organizations of Russia decreased by 265.6 thousand people, and as of January 1,1992 , it was amounted to 1,678 thousand people. The Russian research and development work sphere was characterized by significant differences in the quality of the potential and the results of research and development work of the defense and civil branches of science, the "metropolitan" and peripheral scientific organizations. Most of the scientific organizations had a weak experimental base. The need for scientific instruments was satisfied by $20-25 \%$. The country received less than $1 / 3$ of the world's scientific and technical information. In 1992, centralized purchases of foreign scientific literature practically ceased (GARF, 55: 143). The crisis in science in the last years preceding the collapse of the Soviet Union, led to the fact that serious scientific and technical backlogs have not been created in a number of new areas. As a result, there was a slow renewal of the productive facilities, continued reproduction of obsolete technological structures, "eating away" of huge resources, and increasing disproportions in the economy. This does not exclude the fact that a powerful scientific and technical potential was created in the Soviet Union, which in many ways enabled modern Russia to recover and develop itself.

However, the negative trends that have emerged earlier, only worsened in the so-called "transition period". The demand for scientific and technical products sharply declined; the dramatic reduction of number of orders created a dramatic situation in military science. Noticeably, the outflow of scientists and specialists from scientific research institutes and design bureaus has increased. The social status of the scientist fell steadily, the prestige of science waned, the liberalization of prices caused a sharp (by 10-15 times) increase in material costs and overheads for maintenance of research and development work. In fact, the creation of new objects of science was stopped; the stock of unfinished investment undertakings in the scientific and technical sphere of Russia was 1.5 billion rubles (in the prices of 1991) (GARF, 55: 154155). There was no stable funding, which made it impossible to conduct serious comprehensive research and update the experimental base (ibid). Experts warned the government: "The lack of funds for science in 1992 creates a real threat of irreparable destruction of the scientific and technological potential. This would mean transition of Russia to the category of states incapable of independent development" (GARF, 55: 155).

In this situation, the Ministry of Science, Higher School and Technical Policy of the Russian Federation proposed the concept of reforming the country's scientific and technical potential, the main provisions of 
which were the following: "to reject of the slogan of saving science in general", what presupposes the principle of selectivity for supporting both research and scientific organizations; preservation of the best Russian scientific schools in the field of basic research; demilitarization and conversion of the sphere of research and development in Russia; denationalization of the research and development work sphere and its adaptation to market principles of management; transition from financing of scientific organizations to financing of target projects and programs; providing multiple sources of funding; creation of regional funds to support scientific and technological development; ensuring the social protection of scientific and technical personnel (GARF, 55: 155).

As an urgent measure to preserve Russia's scientific and technological potential, a radical change in the organizational structure and mechanisms of the functioning of science was proposed, and the transition from "departmental, highly militarized, secret research and development" to a model that "would connect the merits of the best traditions of Russian scientific schools with an effective and rigid mechanism of competition in a market economy". In order to achieving this goal in the conditions of the transition period, in particular, from the point of view of the developers, it was required "to transfer applied research mainly to market relations", "to carry out partial privatization in the sphere of scientific research and development work, what would allow getting rid of inefficient scientific organizations". At the same time, it was supposed to provide social protection for scientists (GARF, 55: 155-156). From the point of view of the authors, the solution of these problems required implementation of a number of urgent measures (part of those was specifically identified, and partly was not completely formalized and was declarative). In particular, they had in mind the creation of Russian foundations for basic research and technological development, a fund for the payment of scholarships to talented young scientists; implementation of measures to prevent the withdrawal from the research institutes of experimental production. A package of laws and normative acts regulating the activity of scientific organizations and relations in the sphere of intellectual property was developed, separate tax incentives for scientific and innovative activities were provided for (there are still not enough of them). Authors of the concept believed that such measures in the research and development sphere would create "... prerequisites for preventing the irreversible destruction of the scientific potential of Russia". Recognizing that it "... will be temporarily weakened," the authors at the same time assured that the losses would be "not so great", but at the same time a "base for the future technological revival of Russia" (GARF, 55: 155-156) will be created. It is bitter to read this in 2017, but, probably, the authors were full of optimism and, perhaps, believed that it was necessary to survive only 2-3 difficult years.

Meanwhile according to experts, production was subjected to "technological inflation" which was accompanied by a decrease in the technical level of production due to orientation only on the simplest and commercially riskless technologies. The prestige of the traditional spheres of science and education fell; the interest grew only to what was necessary for utilitarian use in market structures. Renovation of the material and instrument base of science and education has deteriorated. Serious damage to the development of science and technology was caused by the disruption of the existing links and interactions in scientific and technical activities between organizations and enterprises located in the territory of newly emerged states. The absence of foreign currency significantly reduced the scope of international cooperation, deprived them of the opportunity to purchase instruments, equipment, licenses, and scientific literature. The beginning of price liberalization which has not been supported by compensating processes of privatization and demonopolization, caused a sharp increase in material costs, energy costs, etc. which led to a multiple increase (15 times) of overheads related to maintenance research and development. In fact, creation of science objects started in previous years was stopped, the total stock of unfinished investment undertakings in the scientific and technical sphere in Russia was 1.5 billion rubles (in prices of 1991) (GARF, 55: 159). Monthly allocation of funds for science didn't make it impossible to 
plan and conduct research. A powerful tax press, first of all, on profit and value added; land tax which, for example, in Moscow amounted to hundreds of thousands of rubles per hectare per year, did not allow enterprises and scientific organizations to accumulate funds for reinvestments. Exit of pilot productions from the scientific research and educational organizations for commercial gain tend to have mass proportions, what led to the destruction of the technological cycle of research and, as a result, to actual curtailment of work (ibid.).

Market structures (banks, exchanges, trading houses, insurance companies, etc.) did not want to participate in the financing of domestic science. A sharp rise in price (up to 50-70\%) of credit resources forced research institutes to refuse from new loans, what also led to curtailment of research. Decline in the social status of scientists continued. A social status of a scientist did not give special opportunities to increase wages, adequate to the growth of prices, the prestige of the traditional spheres of science and education fell. A significant reduction began in the sphere of science. If the number of workers in the main activity in scientific organizations of Russia only for 1991 decreased by 265.6 thousand people, in the first two months of 1992 the number of workers in science and technology only in Moscow decreased by 120 thousand people or by $14.4 \%$ (ibid.).

Meanwhile, the heads of the Ministry of Science believed that the reduction in the number in the sphere of science cannot be regarded as a negative phenomenon: "Science required the release of "ballast"" (GARF, 55: 160). And officials could not but worry that due to financial difficulties, the most qualified specialists and young people left the scientific organizations for commercial structures or went abroad. The growing "brain drain" process has led to a significant weakening of a number of scientific schools (theoretical physics, genetics, and mathematics). Although the other bothered more, to all appearances: "The bulk of the workers, even upon deliberate deterioration of material conditions, continued to keep their place of employment". And from the point of view of the Ministry of Science, this meant the continuation of "... the consumption of huge financial resources by, in fact, fruitless research institutes" (ibid.).

Simultaneously, during this period, plans were made for the formation of an innovation system in the Russian Federation. If at the same time, we recall the experience of other countries, some of which overcame the crisis and lag in this way, and ensured growth and structural reorganization, they could become alternative to the course taken at the time, and the results could not be so negative. The experience of foreign countries was clearly taken upon compilation of documents (Bodrova et al., 2013). Thus, on June 9, 1992, Chairman of the Innovation Committee of the Russian Federation, the member of the Supreme Economic Council under the Presidium of the Supreme Council, Yu.A. Lebedev sent a letter to the First Deputy Prime Minister V.F. Shumeyko with a request for the preservation of the Innovation Committee, referring to the experience of Western countries (GARF, 53: 188-189). He was refused, but certain typical elements of the innovation infrastructure were reproduced in Russia (funds, science parks, although, some of them operated only on paper).

The materials studied allow us to state that in reality the decisions taken were little correlated with the programs being developed, and with an innovative course; they were aimed at solving immediate tasks, and there was no conceptually elaborated state scientific and technical policy.

Trying to save the remaining work, the leaders of scientific organizations applied to the leadership of the country for additional funding (GARF, 55: 76), but the government's answers were rather laconic: "Due to the difficult economic situation in the country and the difficulties in implementing the republican budget of Russia, allocating additional funds for these purposes from the budget in conditions of acute deficit is currently not possible" (GARF, 55: 89). Such documents testify not only to the financial distress of the 
country at that time, but also to the onset of the collapse of its scientific and technical potential, and about other priorities of the government.

Already at the very beginning of the "transition period", sectoral science was in a particularly difficult situation: branch funds and unified funds for the development of science and technology disappeared. There was a significant reduction in contractual work. Most of the small innovative enterprises, scientific and technical cooperatives and centers created for the development of innovative activities, were engaged in trade and procurement, intermediary and other commercial activities, often using the situation of "orphaned" scientific and technological developments because of the unresolved problem on separation of property rights to scientific and technical funds.

Meanwhile, in the reports of the Ministry of Science sent to the government in January-February 1992, the difficulties experienced by Russian science were explained by the fact that, to a large extent, "science in its essence is a very conservative social system; this predetermines its low adaptive capacity during crises". "Here for today", explained the leadership of the ministry, "in Russia, organizational structures and the usual mechanisms of the functioning of science do not have time to adapt to the rapidly changing conditions of the socioeconomic environment. The structure of the front of research, the distribution of scientific personnel, the established "weights" of sectoral and problematic stocks... absolutely do not correspond to the structure of demand for research and development. In general, today we can state the existence of a deep structural crisis in Russian science" (GARF, 55: 160-161).

In the same year 1992, a letter was sent in the name of the President of the Russian Federation, B.N. Yeltsin by the leaders of a number of leading research institutes, in which, in our opinion, the situation prevailing over the preceding years in the scientific and technical sphere and immediately after the collapse of the USSR was characterized: "In the conditions of price liberalization, the multiple rise in price of raw sources, consumables, fuel, electricity, services, rampant inflation, reduction in capital construction volumes and the limited budget financing of scientific development, according to our calculations, research institutes of building complex will cease to exist in the second quarter of 1992... In 1991, due to a sharp increase in taxes, deductions for social insurance, institutes were forced to reduce the number of employees... According to calculations, in 1992 the institutes must either to reduce the number of employees by almost $50-70 \%$ in 1992 and to turn into small enterprises, or not to reduce, but to establish for all employees a minimum salary of 342 rubles, which, in essence, meant the same thing, the dissolution of organizations. Institutes have no means for any increase in the minimum wage of low-paid employees, and for the payment of benefits to displaced employees, for providing meal to employees who could not afford to go to dining rooms, and for the compensation of transport costs" (GARF, 53: 3940) The authors of the letter arguing that "... the liquidation of the sectoral science will inflict irreparable damage on the Russian construction industry, and the restoration of the current scientific potential in the construction industry will take decades", asked not about additional allocations for the maintenance of sectoral research institutes, "knowing that the state has no money for that", but about abolition of the value-added tax and about reduction of the size of the profit tax, etc. (GARF, 53: 41).

The most serious and critical for the sectoral science and production was that "there have been numerous cases of uncoordinated exit of pilot plants from the structures of research organizations and the reprofiling of pilot production to the production of high-margin products. Such actions were initiated, as a rule, by heads of the pilot plants that act as an independent accounting entity and have the other rights of a legal entity" (GARF, 53: 49). This process was suspended, but it was too late: this entailed destruction of the established process of creating prototypes for new technological equipment, reduction of technological equipment production for machine-building enterprises, reduction of foreign exchange earnings under contracts of NGOs with foreign firms and non-fulfillment of contractual obligations. 


\section{Discussion}

Thus, with the onset of liberal reforms, the situation in the country's scientific and technical complex developed from crisis to catastrophic conditions. First of all, hi-tech industries suffered for that. Collectives of design organizations and academic institutions called with hopes and appeals to the new authorities to preserve scientific facilities, reporting about the outflow of the most active and talented people either abroad or in commercial, mainly intermediary structures; they protested against urgently implemented project on privatization of scientific-technical and educational facilities. And they predicted: "If the situation would not change for the better in the coming months, Russia risks losing its future in science for many years to come" (GARF, 53: 110-111).

These forecasts turned out to be accurate: in the 1990s, instead of the expected breakthrough in the postindustrial society, including through the reform of the old system on organization and management of the scientific and technical complex, its disorganization occurred, and other goals and tasks prevailed. As a result, unique, world-class research teams and outstanding scientific schools have disintegrated in our country. Only for 1991-1993, the number of scientists working in government organizations decreased by almost $40 \%$ (Archive of the State Duma). In the 1990s, the command and planning system for introducing scientific achievements into production was destroyed, the links within the sphere of research and development, science and production were severed, innovation activity was sharply reduced, and sectoral science disintegrated. The commercialization of the scientific and technical sphere has led to a significant reduction in the theoretical level of scientific and technical research.

\section{Conclusion}

Unlike the authors who claim that "... the radically liberal stage of modern Russian modernization" which ensured the transition to market relations, "... was passed relatively quickly, bloodlessly, and surprisingly effectively" (Sogrin, 2001), we make a conclusion about the catastrophic destruction of the scientific and technical complex, first of all, of sectoral science and high-tech industries, and the defense-industrial complex, as a result of the planned (as is proved by documents) de-industrialization of the country, criminal privatization which has been forced in every way, because of the desire to get rid of unnecessary "ballast" in the near post-industrial prosperity and the "brain drain" that followed the similar events, the degradation of science and the education system, the impoverishment of a large part of the population. The survival and partial restoration of certain segments of the scientific and technical sphere can rightfully be equated with a miracle and special ability of Russia to reproduce powerful intellectual resources, in particular, the social strata that liberally-minded researchers refused to call Russian scientific and technical intelligentsia, but in fact, provided in due time industrialization of the country, the implementation of space, nuclear and rocket projects and saved from the complete destruction and plunder of the remnants of the Soviet potential. 


\section{References}

Archive of the State Duma of the Federal Assembly of the Russian Federation. Fund 10100. Series 2. File 703. Sheet 25.

Bodrova, E. V.; Gusarova, M. N. \& Kalinov, V. V. (2013). State scientific and technical policy in the modernization strategy of Russia. Moscow: Publishing House of the Moscow Humanitarian University.

Gordon, A. \& Klopov, E. V. (2001). Losses and acquisitions in Russia in the nineties: Historical and sociological essays on the economic situation of the people's majority. V. 1, 2. Moscow.

Jomo, K. S. (2004). Lessons from the 1997-98 East Asian Crisis. Annual World Bank Conference on Development Economics - Europe. Washington D.C.

Kodin, M. I. (2002). Theoretical and methodological problems of socio-economic and socio-political transformations in Russia in the late $20^{\text {th }}$ century: 1990-2000. Moscow.

Kornai, J. (2000). Ten Years After "The Road to a Free Economy": The Author's Self-evaluation. Paper for the World Bank 'Annual Bank Conference on Development Economics - ABCDE' April 18-20, 2000. Washington D.C.

Krasilshchikov, V. (2008). The Rise and Decline of Catching Up Development: The Experience of Russia and Latin America with Implication for Asian 'Tigers' ( $2^{\text {nd }}$ ed.). Málaga: University of Málaga.

Mau, V. A. (1995). Economics and Power: A Political History of Economic Reform in Russia: 1985-1994. Moscow.

Osipov, G. V. (1999). Reforming of Russia: results and prospects. Social trajectory of the reformed Russia. Novosibirsk.

Plimak, E. G. \& Pantin, I. K. (2000). The drama of Russian reforms and revolutions. Moscow.

Shapiro, H. (2007). Industrial policy and growth. Desa Working Paper No. 53. Economic \& Social Affairs. United Nations. Accessed on 01.09.2017, URL: http://www.un.org/esa/desa/papers/2007/wp53_2007.pdf

Sogrin, V. V. (2001). Political history of modern Russia. 1985-2001: from Gorbachev to Putin. Moscow.

Sukhorukova, S. M.; Pogorelyi, A. M. \& Samorokov, A. V. (2016). Influence of the international technological division of labor on ecological and industrial safety. Russian Technological Journal, 4(13), 7374.

The State Archives of the Russian Federation (GARF). Fund 10265. Series 1. File 53-55.

Zudin, A. (1995). Business and politics in post-communist Russia. Part 1, 2. Moscow. 